\title{
Urolithiasis in male patients: A pilot study on the ethnic differences and clinical
}

\section{profile}

\author{
Sreedharan J1, John LJ ${ }^{2}$, Aly Freeg HAM ${ }^{3}$, Muttappallymyalil J ${ }^{4}$
}

${ }^{1}$ Assistant Director, Statistical Support Facility, CABRI, Gulf Medical University, Ajman, UAE

${ }^{2}$ Lecturer, Department of Pharmacology, Gulf Medical University, Ajman, UAE

${ }^{3}$ Ex-Specialist, Department of Urology, GMC Hospital, Ajman, UAE

${ }^{4}$ Professor, Department of Community Medicine, Gulf Medical University, Ajman, UAE

\section{Chief Editor}

\section{Dr. Indrajit Banerjee}

Technical Editor

Dr. Nishida Chandrasekharan

Formatting Editor

Dr. Brijesh Sathian
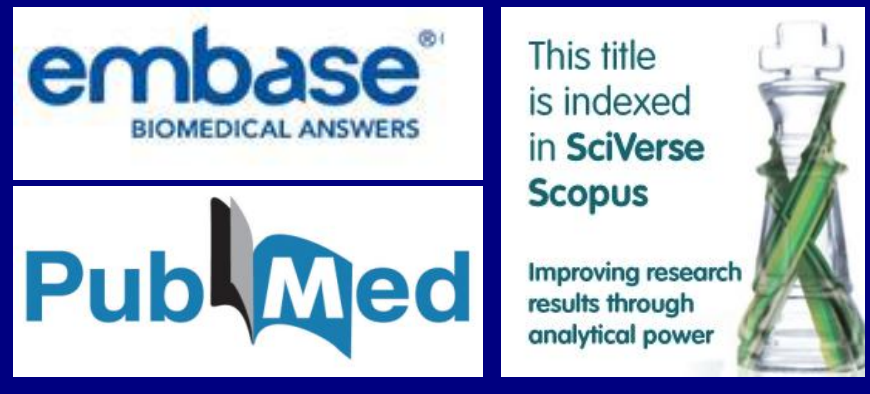

\section{Original Article}

\section{Corresponding Author}

Dr. Jayadevan Sreedharan, PhD

Assistant Director

Statistical Support Facility, CABRI,

Gulf Medical University, Ajman, UAE

E-mail: drjayadevans@gmail.com

\section{Abstract}

\section{Background}

Ethnicity play a role in the occurrence of urinary stones, probably related to climatic, environmental and dietary factors in ethnic groups. The association between ethnicity, age, clinical profile, stone size with type of ureteric stones among males with urolithiasis was studied.

\section{Materials and Methods}

Male patients (>18 years) with lower ureteral stones size $<10 \mathrm{~mm}$ attending outpatient department of Urology, at a private hospital, Ajman over a period of one year were included. Ethics approval was obtained from Institutional Ethics Committee. Data was retrieved from the case records which included socio-demographic variables (age, ethnicity), clinical profile (ureteric colic, duration of pain, other complaints), and laboratory investigations (type of stone, stone size). Descriptive and inferential statistics were performed with SPSS-20 and $\mathrm{p}$ values $<0.05$ considered significant.

Results

185 male patients were included. Mean age was 41.5 (7.3) years, range (22-71) years. Out of the total, 81 (43.8\%) patients were Asians, 81(43.8\%) Arabs and 23 (12.4\%) were of other ethnicity. Most patients (95.1\%) presented with ureteric pain. 49 (26.5\%) had family history of stone disease where calcium oxalate monohydrate and uric acid stones were common, with majority being first degree relation. 


\section{Urolithiasis in male patients}

Data on stone type was available for 90 patients; of which, 21 were calcium oxalate monohydrate, 33-calcium oxalate dehydrate, 24-uric acid and remaining 12 other form of stones. Average age for different types of stone was 38.3, $41.6,39.4$ and 42.8 years for calcium oxalate monohydrate, calcium oxalate dehydrate, uric acid and other types respectively.

\section{Conclusion}

Uric acid stones were more prevalent among Asians and calcium oxalate-dehydrate stones among Arabs. Future studies can be conducted among multiethnic population focusing on dietary pattern and stone analysis.

Keywords: Uric acid stones; urolithiasis; Arabs

\section{Introduction}

The incidence of Ureteral stone disease worldwide is about $5 \%$, with a recurrence rate of $50 \%$ within $5-7$ years of the disease ${ }^{1}$. The life-time risk of urolithiasis worldwide varies from $1-5 \%$ in Asia to $5-9 \%$ in Europe, $10-15 \%$ in United States and $20-25 \%$ in the Middle-East ${ }^{2}$.

The factors identified with the occurrence of ureteric stones include; gender, age, diet, obesity, medications and prior history of renal calculi. Literature on ureteral stone disease have documented that males are at greatest risk of developing urolithiasis ${ }^{3}$. The incidence rate among men is two times higher and the prevalence rate about four times among men higher compared to women. ${ }^{3}$ It is also reported that ages between 20 and 30 years have increased incidence of ureteric stones and the incidence is relatively constant above 30 years until the age of 70 years ${ }^{4}$. The frequency of occurrence of Ureteric stones in a population and the type of ureteric stone may vary with the ethnicity. This may be attributed to the dietary pattern and changes in the climate and environment. In 2010, Akoudad et al reported that race and ethnicity are correlated with occurrence of kidney stones ${ }^{5}$. A survey carried out in the United States noted that the prevalence of ureteric stones among African Americans to be less than $50 \%$ in comparison to the Caucasians and the Mexican Americans ${ }^{6}$.

Several epidemiological studies from the Middle East have documented the increasing incidence of ureteral stone disease in the Gulf region such as United Arab Emirates (UAE), Kuwait, Saudi Arabia, Iran and Bahrain ${ }^{7,8,9}$. The probable reasons for the increasing incidence in this region could be associated with risk factors such as gender, age, diet, and dehydration due to extremely hot weather.

The composition and the type of ureteric stone vary among individuals of different ethnicity as well as geographical conditions; Uric acid stones were reported to be more prevalent among South-east Asian ethnic group and Japanese ${ }^{10,11}$. Calcium oxalate renal stones are common among the other Asian countries such as; India. Nepal and Thailand ${ }^{12-14}$. In the Gulf regions such as Iraq, United Arab Emirates and Saudi Arabia, the predominant type of ureteric stone reported was calcium oxalate stones ${ }^{15-17}$.

The epidemiology of urinary stone disease is noted to increase steadily among the industrialized countries particularly in the urban areas of the developing countries. Understanding the epidemiology of urinary stone disease is important to determine the significance of the disease at a community level, the factors associated with the likelihood of stone occurrence and to raise awareness among those at high risk as a part of the preventive management strategy. Hence, the present study aimed to determine the association between ethnicity, age, clinical profile, size of stones with the type of ureteric stones among male patients with urolithiasis at a private hospital in Ajman, United Arab Emirates.

\section{Materials and Methods}

\section{Research design:}

The present study is subgroup analysis of patients included in a cross sectional study evaluating the efficacy and safety of tamsulosin in lower ureteral stones. The participant details of this study were retrieved from the case record forms of the primary study.

\section{Study population:}

The study population includes male patients attending outpatient department of Urology.

\section{Inclusion criteria:}

In the primary study, the inclusion criteria for the study participants were; all out-patients attending the Department of Urology of both genders, above 18 years of age with lower ureteral stones of size less than $10 \mathrm{~mm}$ confirmed by ultrasonography or non-contrast CT scan and written informed consent. Since it is a documented fact that ureteric stones are prevalent among the male gender, we included only the male patients for this subgroup analysis to explore the ethnic differences and clinical profile in the males.

\section{Exclusion criteria:}

Female patients attending Urology department and Male patients below 18 years were excluded from the study.

\section{Sample size calculation:}

The sample size of the study includes 185 male patients who were considered as the representative samples to achieve the study objective.

\section{Study settings:}

The study was conducted at a private hospital at Ajman, United Arab Emirates.

\section{Duration of study:}

The study was carried out over a period of one year at a private hospital in Ajman.

\section{Study instrument \& validation procedure:}

The data for this study was retrieved from the case record forms of the participants of the primary study. The information retrieved from the subgroup analysis included the socio-demographic variables (age, ethnicity), presence of ureteric colic, side of pain, duration of pain, other adjunctive complaints other than colic pain, the results of laboratory investigations were noted including the type of stone and the stone size. 


\section{Urolithiasis in male patients}

\section{Ethical issues:}

Ethics approval was obtained from the Institutional Ethics Committee before the initiation of the study.

\section{Data management and analysis:}

Primarily, the collected data was fed into an Excel spread sheet. Then it was transferred and analyzed with the help of the SPSS version 20. A complete descriptive analysis of all variables was performed. Inferential statistics was carried out for categorical variables using Chi-square and ANOVA as appropriate. Two sided $p$ values less than 0.05 were considered significant.

\section{Results:}

A total of 185 male patients with ureteral stones were included in the study. The mean age of the patients was 41.5 years with a standard deviation of 7.3 years. The age ranged from minimum 22 years to maximum 71 years. Among the total subjects included, 81 (43.8\%) were of Asian ethnicity, 81(43.8\%) were of Arab ethnicity and 23 (12.4\%) belonged to other ethnic groups. Of the total patients, only $49(26.5 \%)$ reported family history of stone disease. On further exploring the degree of relation among the family members with urolithiasis it was revealed that all of them were of the first degree relation (Father-30.6\%, brother$28.6 \%$, mother-26.5\% and sister-14.3\%).

In the clinical presentation of these patients, most of the patients $(95.1 \%)$ reported with ureteric colic pain, of which more than $85 \%$ complained of unilateral colic pain. The mean duration of pain was 4.1 days with a standard deviation of 3.4 days (range minimum one day to 30 days). The demographic and clinical profile of the patients with ureteric stones has been listed in table-1.

The information on the type of stone in these patients was available for 90 patients. Calcium oxalate dehydrate stones was the most common stone type followed by calcium oxalate monohydrate stones and uric acid stones as shown in Figure-1.

The average age of the patients with different types of stone were 38.3 years, 41.6 years, 39.4 years and 42.8 years for calcium oxalate monohydrate, calcium oxalate dehydrate, uric acid and other forms of stone patients respectively.

On analyzing the type of stones reported in different ethnic groups, it was found that uric acid stones were more common among the Asians compared to calcium oxalate stones, but it was not statistically significant. It was also noted that the calcium oxalate dehydrate stones were more commonly reported among the Arab ethnic group.

On cross tabulating family history of ureteral stones and the type of stones reported it was observed that those patients without any family history of urolithiasis, calcium oxalate dihydrate stones were more frequently reported compared to the other types of stones, and patients with a positive family history of urolithiasis, calcium oxalate monohydrate and uric acid stones were the more frequent. It was also noted that most of the calcium oxalate monohydrate and uric acid stones were of the size less than six $\mathrm{mm}$ while the calcium oxalate dihydrate stones were more frequently of size greater than six $\mathrm{mm}$. The cross tabulation between the type of stones versus the ethnicity, family history of stones and stone size is illustrated in table- 2 .

\section{Figure- 1: Types of ureteric stones reported in patients}

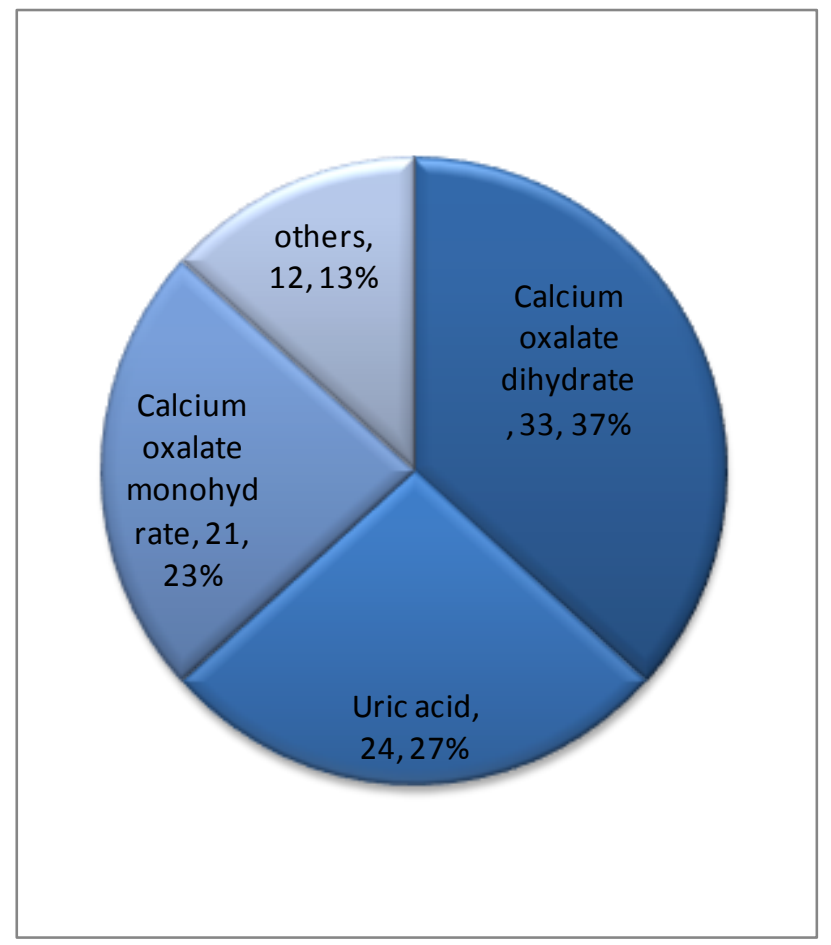

\section{Discussion}

The present study aimed to determine if any difference exists in the types of stone with ethnicity. In this study ethnicity refers to a category of people who share the same cultural heritage. Several studies have reported the role of ethnicity in the risk of developing urinary stones. Some studies have reported that the association between geographical area and the incidence of urolithiasis ${ }^{18,19}$.

\section{Kidney stone disease and Ethnicity:}

Previous reports from the United States have documented that the prevalence of kidney stone disease to be highest among whites and lowest in African Americans after adjusting the age, gender and other variables ${ }^{5,6}$. In yet another cross-sectional study from the United States observed that the highest prevalence of kidney stones was among the white population, while Hispanic and Asians had an intermediate prevalence and lowest was noted among the black population ${ }^{20}$.

Biochemical variations in the urine and Ethnicity: Most of these studies have reported regarding the biochemical variations in the urine sample, variation in incidence and prevalence of urolithiasis in different ethnic groups. With regard to biochemical variation, a study among Asians and white patients observed a significantly greater excretion of uric acid and significantly lower citrate, magnesium, phosphate and creatinine among Asians compared to the whites. The study also reported that there is no significant difference in 24-hour urine volume, $\mathrm{pH}$, or excretion of calcium, oxalate, potassium, sodium or sulfate between Asians and Whites ${ }^{21}$. 
Table- 1: Demographic and clinical profile of patients with ureteric stones

\begin{tabular}{|c|c|c|c|}
\hline Variable & Group & Frequency & Percentage \\
\hline \multirow{3}{*}{ Ethnicity } & Asian & 81 & 43.8 \\
\hline & Arab & 81 & 43.8 \\
\hline & Others & 23 & 12.4 \\
\hline \multirow{3}{*}{ Age (years) } & $<=35$ & 29 & 15.7 \\
\hline & $36-50$ & 135 & 73.0 \\
\hline & $>50$ & 21 & 11.4 \\
\hline \multirow{2}{*}{ Past history of stone disease } & Yes & 50 & 27.0 \\
\hline & No & 135 & 73.0 \\
\hline \multirow{2}{*}{ Family history of stone disease } & Yes & 49 & 26.5 \\
\hline & No & 136 & 73.5 \\
\hline \multirow{3}{*}{ Symptoms } & Ureteric colic & 176 & 95.1 \\
\hline & Hematuria & 102 & 55.1 \\
\hline & Dysuria & 107 & 57.8 \\
\hline \multirow{4}{*}{ Duration of pain in days ( $n=176)$} & $1-2$ & 53 & 30.1 \\
\hline & 3-4 & 71 & 40.4 \\
\hline & $5-6$ & 23 & 13.0 \\
\hline & $>/=7$ & 29 & 16.5 \\
\hline \multirow{2}{*}{ Side of pain ( $n=176)$} & Unilateral & 151 & 85.8 \\
\hline & Bilateral & 25 & 14.2 \\
\hline \multirow{4}{*}{ Pain episodes ( $n=176$ ) } & 1 & 6 & 3.4 \\
\hline & 2 & 19 & 10.8 \\
\hline & 3 & 50 & 28.4 \\
\hline & 4 and more & 34 & 19.3 \\
\hline
\end{tabular}

Table- 2: Type of stones Vs. Ethnicity, family history of stones and stone size

\begin{tabular}{|c|c|c|c|c|c|c|c|c|c|}
\hline \multirow{3}{*}{ Variables } & \multirow{3}{*}{ Group } & \multicolumn{8}{|c|}{ Stone type } \\
\hline & & \multicolumn{2}{|c|}{$\begin{array}{c}\text { Calcium oxalate } \\
\text { monohydrate }\end{array}$} & \multicolumn{2}{|c|}{$\begin{array}{l}\text { Calcium oxalate } \\
\text { dihydrate }\end{array}$} & \multicolumn{2}{|c|}{ Uric Acid } & \multicolumn{2}{|c|}{ Others } \\
\hline & & No. & $\%$ & No. & $\%$ & No. & $\%$ & No. & $\%$ \\
\hline \multirow{4}{*}{ Ethnicity } & Asian & 6 & 20.0 & 9 & 30.0 & 10 & 33.3 & 5 & 16.7 \\
\hline & Arab & 11 & 22.9 & 22 & 45.8 & 11 & 22.9 & 4 & 8.3 \\
\hline & others & 4 & 33.3 & 2 & 16.7 & 3 & 25.0 & 3 & 25.0 \\
\hline & Total & 21 & -- & 33 & -- & 24 & -- & 12 & -- \\
\hline \multirow{3}{*}{$\begin{array}{l}\text { Family } \\
\text { history }\end{array}$} & Yes & 5 & 31.3 & 2 & 12.5 & 5 & 31.3 & 4 & 25.0 \\
\hline & No & 16 & 21.6 & 31 & 41.9 & 19 & 25.7 & 8 & 10.8 \\
\hline & Total & 21 & -- & 33 & -- & 24 & -- & 12 & -- \\
\hline \multirow{3}{*}{$\begin{array}{l}\text { Stone size } \\
\text { (in } \mathrm{mm} \text { ) }\end{array}$} & $<=6$ & 10 & 52.6 & 12 & 38.7 & 11 & 52.4 & 3 & 30.0 \\
\hline & $>6$ & 9 & 47.4 & 19 & 61.3 & 10 & 47.6 & 7 & 70.0 \\
\hline & Total & 19 & -- & 31 & -- & 21 & -- & 10 & -- \\
\hline
\end{tabular}


Incidence of urinary stone and types of stones with ethnicity:

Maloney et al. reported that the incidence of urinary stone disease is similar in Whites and Nonwhites ${ }^{22}$. Pak et al. reported that there is considerable similarity in the urinary stone disease presentation throughout the world ${ }^{19}$. The present study results revealed that the uric acid stones were more common among the Asians compared to calcium oxalate stones. Calcium oxalate dehydrate stones were more commonly reported among the Arab ethnicity compared to other types of stones. This finding is in line with previous studies reported from the Gulf regions such as Iraq, United Arab Emirates and Saudi Arabia ${ }^{15-17}$.

\section{Influence of diet and climate on types of stone:}

The difference in the types of stone and ethnicity may be related to the type of diet consumed by the different ethnic groups. Pak et al. and Maloney et al. also reported that the difference in the ethnicity may be due to nutritional, environmental and socio-economic factors and not due to ethnicity alone ${ }^{19,22}$. It has been documented that in the Gulf region the consumption of oxalate is nearly threefold higher than the Western world thus, increasing the risk of calciumoxalate stone formation. The risk of ureteric stone formation is further increased by low urine volume due to the climatic influence in the region ${ }^{7}$.

\section{Conclusion}

This study illustrated that there is a probable association between ethnicity and ureteric stones, uric acid stones were more prevalent among Asians and calcium oxalate dehydrate stones among the Arabs.

The future scope of the study lies in the further investigation on a large scale basis to adopt suitable preventive measures against the formation of renal calculi. Aspects of seasonal variation, smoking history and alcohol consumption also need further investigation to enable fair comparisons of global trends in prevalence of ureteric calculi. Advanced studies among multiethnic population focusing on detailed dietary pattern and stone analysis can establish the causal effect between ethnicity and type of ureteric stone.

\section{Limitations of the study:}

Dietary pattern and seasonal variation of the stone was not studied in this study which could probably influence the occurrence of ureteral stones.

Sample size in the present study was relatively small hence it could hinder representation of the findings to the entire population and may not depict the true prevalence and profile of patients with ureteric stones at national level. This limitation could be overcome by extending the study to other hospitals and health centers across the country.

\section{Acknowledgement}

The authors are thankful to the institution, Gulf Medical University for giving permission to conduct this valuable research and GMC hospital, Ajman for constant support in making it successful.

\section{Urolithiasis in male patients}

\section{Author's Contribution:}

JS,LJJ participated in designing and development of proposal, data collection, data analysis, statistical analysis. HAF, JS, LJ supervised and performed the final data analysis, read, edited and approved the manuscript before submission. JS participated in data analysis and statistical analysis. JM proof read and edited the proposal and reviewed the manuscript.

\section{Conflict of interest:}

There is no conflict of interest among authors arising from the study.

\section{References:}

1. Parmar MS. Kidney stones. Br J Urol. 2004; 328:1420.

2. Bartoletti R, Cai T, Mondaini N, Melone F, Travaglini F, Carini $M$, et al. Epidemiology and risk factors in urolithiasis. Urol Int. 2007;79(suppl 1):3-7. http://dx.doi.org/10.1159/000104434

3. Trinchieri A. Epidemiology of Urolithiasis: an update. Clin Cases Miner Bone Metab. 2008; 5(2):101-106.

4. Hughes P; Caring for Australians with Renal Impairment (CARI). The CARI guidelines. Kidney stones epidemiology. Nephrology (Carlton). 2007; 12 (Suppl 1): s26-30.

http://dx.doi.org/10.1111/j.1440-1797.2006.00724.x

5. Akoudad S, Szklo M, McAdams MA, Fulop T, Anderson CA, Coresh J, et al. Correlates of kidney stone disease differ by race in a multi-ethnic middle-aged population: the ARIC study. Prev Med. 2010; 51(5):41620.

\section{http://dx.doi.org/10.1016/j.ypmed.2010.08.011}

6. Stamatelou KK, Francis ME, Jones CA, Nyberg LM, Curhan GC. Time trends in reported prevalence of kidney stones in the United States: 1976-1994. Kidney Int. 2003; 63(5):1817-1823. http://dx.doi.org/10.1046/j.1523-1755.2003.00917.x

7. Robertson WG. Stone formation in the Middle Eastern Gulf States: A review. Arab J Urol. 2012; 10(3):265-272.

http://dx.doi.org/10.1016/j.aju.2012.04.003

8. Safarinejad MR. Adult urolithiasis in a populationbased study in Iran: prevalence, incidence, and associated risk factors. Urol Res. 2007; 35:73-82. http://dx.doi.org/10.1007/s00240-007-0084-6

9. Qadami E, Ampoon A, Manansala, NH. The prevalence and clinical profile of patients diagnosed with renal calculi at the American Mission Hospital in the Kingdom of Bahrain. J Bahrain Med Soc. 2013; 24(2): 62-65.

10. Portis AJ, Hermans K, Culhane-Pera KA, Curhan GC. Stone disease in the Hmong of Minnesota: Initial description of a high-risk population. J Endourol. 2004; 18:853-7 


\section{http://dx.doi.org/10.1089/end.2004.18.853}

11. Kuruma $H$, Arakawa $T$, Kubo S, Hyodo $T$, Matsumoto K, Satoh T, Egawa S, Baba S. Ammonium acid urate urolithiasis in Japan. Int J Urol. 2006; 13:498-501. http://dx.doi.org/10.1111/j.1442-2042.2006.01348.x

12. Ansari MS, Gupta NP, Hemal AK, Dogra PN, Seth A, Aron $M$, et al. Spectrum of stone composition: Structural analysis of 1050 upper urinary tract calculi from northern India. Int J Urol. 2005; 12:12-624. http://dx.doi.org/10.1111/j.1442-2042.2004.00990.x

13. Risal S, Risal P, Pandeya DR, Adhikari D, Bhattachraya CS, Singh PP, Shrestha ML. Spectrum of stones composition: a chemical analysis of renal stones of patients visiting NMCTH. Nepal Med Coll J. 2006; 8:263-5.

14. Tanthanuch M, Apiwatgaroon A, Pripatnanont C. Urinary tract calculi in southern Thailand. J Med Assoc Thai. 2005; 88:80-5.

15. Qaader DS, Yousif SY, Mahdi LK. Prevalence and etiology of urinary stones in hospitalized patients in Baghdad. East Mediterr Health J. 2006; 12:853-61.

16. Hammad FT, Kaya M, Kazim E. Bladder calculi: did the clinical picture change? Urology. 2006; 67:1154-8. http://dx.doi.org/10.1016/j.urology.2005.12.038

17. Khan $A S$, Rai ME, Gandapur, Pervaiz A, Shah $A H$, Hussain AA, Siddiq M. Epidemiological risk factors and composition of urinary stones in Riyadh Saudi Arabia. J Ayub Med Coll Abbottabad. 2004; 16:56-8.

18. Soucie JM, Coates RJ, McClelllan W, Austin H, Thun M. Relation between Geographic variability in kidney stones prevalence and risk factors for stones. Am J Epidemiol 1996; 143:487-495. http://dx.doi.org/10.1093/oxfordjournals.aje.a008769

19. Pak CY, Resnick MI, Preminger GM. Ethnic and geographic diversity of stone disease. Urology. 1997; 50(4):504-7.

http://dx.doi.org/10.1016/S0090-4295(97)00307-5

20. Soucie JM, Thun MJ, Coates RJ et al. Demographic and geographic variability of kidney stones in the United States. Kidney Int. 1994; 46:893-9. http://dx.doi.org/10.1038/ki.1994.347

21. Eisner BH, Porten SP, Bechis SK, Stoller ML. The Role of Race in Determining 24-Hour Urine Composition in White and Asian/Pacific Islander Stone Formers. The J. of Urology 2010; 183:1407-1411. http://dx.doi.org/10.1016/j.juro.2009.12.033

22. Maloney ME, Springhart WP, Ekeruo WO, Young MD, Enemchukwu CU, Preminger GM. Ethnic background has minimal impact on the etiology of nephrolithiasis. J Urol. 2005; 173(6):2001-4. http://dx.doi.org/10.1097/01.ju.0000159076.70638.1e

\section{Article Information}

\section{Article history}

Received

$10^{\text {nd }}$ July 2014

Received in revised form $18^{\text {th }}$ August 2014

Accepted $19^{\text {rd }}$ September 2014 